\title{
Research methods in international business: The challenge of complexity
}

\author{
Lorraine Eden ${ }^{1}$ and \\ Bo Bernhard Nielsen ${ }^{2,3}$
}

\author{
${ }^{1}$ Department of Management, Mays Business \\ School, Texas A\&M University, TAMU 4221, \\ College Station, TX 77843-4221, USA; ${ }^{2}$ Discipline \\ of International Business, The University of Sydney \\ Business School, Abercrombie Building H7O, \\ Corner Abercrombie Street and Codrington St, \\ Darlington, NSW 2006, Australia; ${ }^{3}$ Department of \\ Strategy and Innovation, Copenhagen Business \\ School, Kilevej 14, 2000 Frederiksberg, Denmark \\ Correspondence: \\ L Eden, Department of Management, Mays \\ Business School, Texas A\&M University, \\ TAMU 4221, College Station, TX 77843-4221, \\ USA \\ e-mail: leden@tamu.edu
}

\begin{abstract}
International business (IB) research is designed to explore and explain the inherent complexity of international business, which arises from the multiplicity of entities, multiplexity of interactions, and dynamism of the global economic system. To analyze this complexity, IB scholars have developed four research lenses: difference, distance, diversity, and disparity. These four lenses on complexity have created not only unique research opportunities for IB scholarship but also unique research methodological challenges. We therefore view complexity as the underlying cause of the unique methodological challenges facing international business research. We offer several recommendations to help IB scholars embrace this complexity and conduct reliable, interesting, and practically relevant research.
\end{abstract}

Journal of International Business Studies (2020) 51, I609-1620.

https://doi.org/ 10.1057/s4 I 267-020-00374-2

Keywords: international business research; complexity; multiplicity; multiplexity; dynamism; difference; distance; diversity; disparity; research methods; methodology

\section{INTRODUCTION}

It is a well-accepted fact that high-quality research methods are a necessary building block for strong scholarship in international business (IB) research. Many scholars have written about the methodological challenges that can bedevil scholarship in IB and other disciplines and have recommended best practices for dealing with these challenges. For example, see the wide variety of methodology challenges discussed in Eden, Nielsen and Verbeke (2020) and recent papers by Aguinis and co-authors (Aguinis, Cascio \& Ramani, 2017; Aguinis, Hill \& Bailey, 2019; Aguinis, Ramani \& Alabduljader, 2018; Bergh, Sharp, Aguinis \& Li, 2017).

The new JIBS Point article by Aguinis, Ramani and Cascio (2020) follows in this tradition, providing a useful analysis of the "four most pervasive contemporary methodological choices faced by international business (IB) researchers." Our interest lies in the unique aspects of IB research and thus our paper is designed to serve as a Counterpoint and complement to their JIBS Point article. We argue that IB research questions are designed to explore and explain the inherent complexity of the global economy, which is generated by three factors: multiplicity of entities (i.e., number and variety of actors, industries, countries, institutions, etc.),
Received: 31 August 2020

Accepted: 4 September 2020

Online publication date: 28 October 2020 
multiplexity of interactions (i.e., number and variety of ties or relationships among these entities), and dynamism over time (i.e., changing nature of the international business system). To analyze the complexity of the IB system, scholars have developed four lenses of research, which we refer to as the "four D's" (difference, distance, diversity, and disparity). These four lenses on complexity have created unique research opportunities for IB scholars but have also presented unique research methodology problems. We therefore argue that complexity is the underlying cause of the unique methodological problems facing international business research.

Our Counterpoint article first highlights Aguinis et al.'s (2020) helpful advice for improving the quality of IB research and discusses some of the article's limitations. We then turn to developing our thesis on the complexity of IB research, the four research lenses that can be used to analyze complexity, their resulting methodological problems, and proposed methodology solutions.

\section{A BRIEF ASSESSMENT OF AGUINIS ET AL. (2020)}

\section{Contributions}

Aguinis et al.'s (2020) article on challenges and recommended best practices in IB research methodology is a welcome addition to the literature on this topic. The authors identified the most pervasive methodological challenges faced by IB researchers by counting the self-reported research methodology problems in the 43 empirical articles published in the 2018 volume of the Journal of International Business Studies (JIBS). Using this method, Aguinis et al. (2020) identified four methodological challenges (percentage of JIBS articles in brackets): psychometrically deficient measures (73\%), idiosyncratic samples or contexts (62\%), less-thanideal research designs (62\%), and insufficient evidence about causal relations (8\%). The authors explored each challenge and proposed some solutions.

The most frequently mentioned challenge (in almost three-quarters of the JIBS articles) was that the measures used were psychometrically deficient; i.g., the measures did not fully capture the construct or were not sufficiently reliable. Aguinis et al. (2020) proposed three solutions. IB scholars should: (1) determine whether the measure has been used previously to represent a different construct and, if so, demonstrate why their conceptualization is appropriate; (2) specify whether the construct is reflective or formative and, depending on the answer, apply the appropriate analytical technique; and (3) use multiple indicators to measure the construct.

The second and third challenges were reported in identical percentages of JIBS papers (62.2\%), suggesting that JIBS authors coupled the two challenges together. Examples of the second challenge, idiosyncratic samples or contexts, included testing IB theories in a single country or market or during a particular time period. Solutions proposed by Aguinis et al. (2020) were to (1) treat the sample as an opportunity to go deeper, rather than as a limitation, and (2) choose unique or extreme samples or contexts. The third challenge, lessthan-ideal research designs, involved questions such as multiple levels of analysis and common method variance. Recommended solutions were to (1) use Big Data to create unique insights and (2) leverage Big Data techniques to re-analyze currently available data.

The fourth challenge, insufficient evidence to infer causal relations, was reported by very few JIBS authors. Those who mentioned this issue referenced comments regarding distinguishing causality from correlation and the inability of current research methods to answer causality. To address this issue, Aguinis et al. (2020) proposed that JIBS authors use (1) quasi-experimental designs and (2) necessary-conditions analysis.

\section{Limitations}

The JIBS Point article by Aguinis et al. (2020) addresses important methodological issues. The article, however, suffers from at least three limitations, which we discuss below.

First, only one year of JIBS (2018) empirical articles was analyzed. While there is no reason to think that 2018 was an outlier year, there would have been several benefits to analyzing a longitudinal dataset. Longitudinal data allow for a more informed discussion of the limitations over time (and hence potential changes/evolutions) and provide potentially deeper insights into the importance of these limitations.

Table 1 provides some information on the general types of research methods employed by JIBS authors during the first 50 years of the journal. Of the 1265 empirical articles, nearly 30\% (372 articles) were published in the most recent decade (2010-2019). Most of these 372 articles (86\%) used 
Table 1 Distribution of JIBS articles by research methodology, 1970-2019. Source: Authors' calculations based on data provided by Nielsen et al. (2020)

\begin{tabular}{|c|c|c|c|c|c|c|}
\hline JIBS articles by research method & $1970 \mathrm{~s}$ & $1980 s$ & $1990 \mathrm{~s}$ & $2000 s$ & $2010 s$ & Total \\
\hline Quantitative (AQ + SQ) Articles & 79 & 133 & 223 & 343 & 319 & 1097 \\
\hline Share of this decade & 0.775 & 0.796 & 0.899 & 0.912 & 0.858 & 0.867 \\
\hline Share of this method & 0.072 & 0.121 & 0.203 & 0.313 & 0.291 & 1.000 \\
\hline Archival Quantitative (AQ) & 38 & 71 & 106 & 178 & 230 & 623 \\
\hline Share of this decade & 0.373 & 0.425 & 0.427 & 0.473 & 0.618 & 0.492 \\
\hline Share of this method & 0.061 & 0.114 & 0.170 & 0.286 & 0.369 & 1.000 \\
\hline Survey quantitative (SQ) & 41 & 62 & 117 & 165 & 89 & 474 \\
\hline Share of this decade & 0.402 & 0.371 & 0.472 & 0.439 & 0.239 & 0.375 \\
\hline Share of this method & 0.086 & 0.131 & 0.247 & 0.348 & 0.188 & 1.000 \\
\hline Qualitative articles & 16 & 18 & 8 & 20 & 35 & 97 \\
\hline Share of this decade & 0.157 & 0.108 & 0.032 & 0.053 & 0.094 & 0.077 \\
\hline Share of this method & 0.165 & 0.186 & 0.082 & 0.206 & 0.361 & 1.000 \\
\hline Mixed methods articles & 7 & 16 & 17 & 13 & 18 & 71 \\
\hline Share of this decade & 0.069 & 0.096 & 0.069 & 0.035 & 0.048 & 0.056 \\
\hline Share of this method & 0.099 & 0.225 & 0.239 & 0.183 & 0.254 & 1.000 \\
\hline Total JIBS articles ${ }^{a}$ & 102 & 167 & 248 & 376 & 372 & 1265 \\
\hline Share of this decade & 1.000 & 1.000 & 1.000 & 1.000 & 1.000 & 1.000 \\
\hline Share of total (1970-2019) & 0.081 & 0.132 & 0.196 & 0.297 & 0.294 & 1.000 \\
\hline
\end{tabular}

Italicized numbers represent share of the total

a This table only includes JIBS publications using quantitative, qualitative, or mixed methods. The table excludes articles that are, for example, conceptual, theoretical, or editorial in nature.

quantitative methods (archival or survey); another 9\% used qualitative methods; and the remainder (5\%) used mixed methods. Clearly evident over the 50 -year time period are the shifts in the relative importance of different research methods. Notable has been the growing importance of archival methods, which almost doubled from $37 \%$ as a proportion of all JIBS empirical papers in the 1970 s to $62 \%$ in the 2010 s, and the decline of survey methods, which fell by almost half (from $40 \%$ to $24 \%$ ) of empirical papers over the same years. Papers using qualitative methods fell from $16 \%$ in the 1970 s to a low of $3 \%$ in the 1990 s and have now rebounded to $9 \%$ in the 2010 s.

It is therefore possible that examining one year rather than several years may have affected the relative shares of methods used and the resulting methodological challenges, or at least the frequencies of reports, identified in Aguinis et al. (2020). For example, the relatively low percentage given to challenge \# 4 (inference of causality) may have been due to the few survey papers in JIBS that year. Following the example of Brutus, Aguinis, and Wassmer (2013), which according to the authors was influential for their article methodologically, we conclude that at least five and preferably 10 years of data would have been helpful for understanding why JIBS authors identified particular research challenges and not others.
A second limitation is that the method used by Aguinis et al. (2020) was counting self-reports by JIBS authors. This is problematic for several reasons. First, the simple yardstick used (counting zero or one for whether the authors of a JIBS article mentioned a methods problem or not) is a coarse measure and not very informative. For example, it would have been useful to know whether, after having listed a methodological problem, the JIBS authors also explained whether and how they tried (or did not try) to address the problem. Second, the JIBS authors' own assessment of the problem would have been helpful. Did they see the methodological challenge as material (i.e., could it have substantially affected the outcome of the paper) and, if so, did they assess what the likely impact would have been? Third, perhaps the IIBS authors may have gone further and identified in their paper why they had not addressed the challenge (e.g., they saw the issue as non-material, appropriate data did not exist at this point in time, or there was no method available to handle this particular problem). Fourth, a deeper analysis could have looked at whether there really was a problem or not, in other words, did the JIBS authors list too many or too few problems? Lastly, JIBS authors know they are expected to have a Discussion section where they discuss the limitations of their paper (e.g., Aguinis and his co-authors also follow this convention). 
Were the JIBS authors simply "checking the box" in their Limitations section? In sum, a comprehensive analysis of the research methodology problems in current JIBS articles would have benefitted from a much deeper assessment of the original JIBS articles. Given the focus on a single year and resulting limited number of articles (43), the "case study" approach (Aguinis et al., 2020) to analyzing JIBS methodological challenges falls somewhat short of meeting its goals.

A third and perhaps the most important limitation of Aguinis et al. (2020) from our perspective is that their four identified core research methodology issues are not unique to IB research. While the percentages may differ across disciplines (see their discussion regarding Brutus et al.'s (2013) assessment of management journal articles), the identified methodological problems and proposed solutions appear to be common across business and psychology journals rather than unique to IB research. The authors acknowledge this, noting that they used JIBS as a case study: "Secondly, our focus on recent JIBS articles is not intended to target this journal, or more broadly, the field of IB. For example, authors of articles published in Academy of Management Journal (AMJ), Strategic Management Journal (SMJ), Journal of Management (JOM), and Journal of Applied Psychology (JAP) have identified some of the challenges also referred to by JIBS authors" (Aguinis et al., 2020).

\section{Assessment}

Self-reports by JIBS authors in 2018, as identified in Aguinis et al. (2020), suggest that IB research currently faces four major methodological challenges: measures, samples, research design, and causality. We applaud the authors' efforts to address these important issues but have some concerns about the methods used in their paper and the lack of adequate attention to contextual influences resulting from the complexity of IB phenomena. Moreover, some of their challenges and solutions appear to be "micro" in nature, focusing on issues that may present major problems for scholars engaged in predominantly quantitative (survey) studies with particular psychometric properties (e.g., reflective versus formative measures and multiple versus single indicators to measure constructs). We conclude that their article makes a valuable contribution but should be treated with caution and recommend that IB scholars read both the JIBS Point and Counterpoint articles together.

\section{Other Studies}

For comparison purposes, we searched for other studies that have used methods similar to Aguinis et al. (2020) and Brutus et al. (2013) to identify methodology challenges relevant to IB research. We highlight two below and also acknowledge Andersen and Skaates (2004).

Peterson (2004) examined the research methods used in 124 international management (IM) articles published in three journals (JIBS, AMJ, and Administrative Sciences Quarterly (ASQ)) between 1990 and 1999. His analysis identified five methodological concerns in IM research: (1) non-representative or within-country samples, (2) limited data sources (only one or two countries), (3) lack of author diversity (one or two authors from the same country), (4) lack of examination of cross-cultural/national differences, and (5) excessive reliance on one research method (typically correlations and regressions), so that neither causality and nuances could be addressed. His proposed five solutions, respectively, were: (1) samples drawn from the whole country, (2) larger sample populations with more countries over at least 5-10 years, (3) cross-national research teams that meet periodically, (4) the use of standardized survey and research methods across countries, and (5) the use of multiple (mixed) research methods.

A second comparative study is Coviello and Jones (2004), which used content analysis to examine 55 articles on international entrepreneurship (IE) published in ten business journals (including JIBS) between 1989 and 2002. The authors assessed the articles in terms of four methods issues: (1) time frame and content, (2) sample, (3) data collection and analysis, and (4) cross-national equivalence. Their key criticisms were that most articles involved static cross-country or cross-industry comparisons, had inconsistent definitions and measures of key variables, used idiosyncratic samples that led to results that were difficult to generalize, and did not capture complex processes well. Coviello and Jones (2004) argued that these methodological problems were inherent in the complexities involved in doing IE research. The authors concluded that IE scholars needed to take a multidisciplinary approach, adopt dynamic research designs that integrated positivist and interpretivist methodologies, and incorporate time as a key dimension.

Both Peterson (2004) and Coviello and Jones (2004) highlight similar complexities involved in 
doing IB research, despite their focus on different disciplines (management vs. entrepreneurship). Both articles stress that core methodological problems are caused by differences and diversities in cultures and contexts that are dynamic not static in nature. We concur with their assessment and go further to argue below that complexity is the underlying source of the unique methodological challenges faced by international business scholars.

\section{THE COMPLEXITY OF IB RESEARCH}

We of course agree with Aguinis et al. (2020) that IB researchers face many methodological problems and choices. Our interest lies, however, less in the commonalities of these problems with other disciplines and more with the unique methodological concerns that are specifically "IB"; i.e., caused by research questions and cross-border contexts typically studied by IB scholars and published in JIBS, some of which are highlighted in Peterson (2004) and Coviello and Jones (2004).

\section{Complexity in IB Research}

We start with a simple metaphor explaining why IB is different from mainstream disciplines like management and psychology. Eden (2008) suggested that a helpful way to understand IB research is to conceptualize a matrix where the columns are the disciplines or functional areas of business (e.g., management, entrepreneurship, finance) and the rows are the topics typically covered in these disciplines (e.g., markets, firm strategy, performance, international). IB research can therefore be viewed as the "international" row that cuts across the "discipline" columns.

Eden (2008) argued that JIBS researchers are boundary-spanners; they emphasize the adjective "international" over the noun of their particular discipline or university department. Implicit in this approach is the insight that IB researchers are not only engaged in studying business in cross-border contexts but also in cross-cultural and cross-disciplinary contexts. The domain of IB research is, in effect, a big umbrella covering the international/ cross-border aspects of all business disciplines. Thus, IM and IE can be viewed as subfields of IB (see also discussions in Eden, Dai and Li (2010) on IM and IB and in Verbeke \& Ciravegna (2018) on IE and IB).

The variety and breadth of research topics in the IB domain is therefore huge, ambitious, and challenging (Table 2). As a result, there is an inherent complexity to IB research that is different from domestically focused scholarship, and the research methodology challenges faced by IB researchers should not be simply conflated with methodological issues facing scholars in mainstream disciplines.

We believe there are three key sources to the complexity of IB research, which we illustrate in Figure 1: multiplicity, multiplexity, and dynamism. The first source of complexity is the multiplicity (i.e., the number and variety) of entities (e.g., actors, industries, countries, contexts, cultures, institutions) in the global economic system. While often pictured as a dyad (home versus foreign), in reality most IB studies involve multiple actors in multiple countries in multiple contexts. Multiplicity creates both opportunities and problems for IB research; see, for example, the discussions in Buckley and Casson (2001), Peterson (2004), Coviello and Jones (2004), and Teagarden, Von Glinow and Mellahi (2018).

Multiplicity, which Buckley and Casson (2001) refer to as "combinatorial complexity", can be addressed in many ways. Buckley and Casson recommend using parsimony and simplifying, rational-actor techniques such as real options and game theory; they provide several examples of how these techniques can be used to analyze problems such as mode of entry and location choice. Applying rational-actor economics to multiplicity has clear benefits but also some costs (Samuels, 1995). Other possible approaches focus more on how cross-border activities exacerbate the joint challenges of managing bounded rationality, unreliability, and investments in specific assets. Here conceptual tools from comparative institutional analysis and empirical tools such as fuzzy-set qualitative comparative analysis, as well as a variety of multi-level analysis tools, can be helpful (see Eden et al. (2020) for discussions of appropriate techniques).

The second factor contributing to complexity of the global economy and thus of IB research is the multiplexity of interactions (the number and variety of relationships and interdependencies) among these entities, which Buckley and Casson (2001) refer to as "organic complexity." IB scholars have studied multiplexity for many years in contexts such as the MNE's inter- and intra-organizational networks, buyer-supplier networks using lean production technologies, and international strategic alliances (Cuypers, Ertug, Cantwell, Zaheer \& Kilduff, 2020). Multiplexity is created when there are 
Table 2 The domain of international business studies. Source: Eden (2008: 3)

The activities, strategies, structures, and decision-making processes of multinational enterprises; Interactions between multinational enterprises and other actors, organizations and institutions;

The cross-border activities of firms (e.g., intrafirm trade, finance, investment, technology transfers, offshore services);

How the international environment (e.g., cultural, political, economic) affects the activities, strategies, structures, and decisionmaking processes of firms;

Comparative studies of businesses, business processes and organizational behavior in different countries and environments; and The international dimensions of organizational forms (e.g., strategic alliances, mergers, and acquisitions) and activities (e.g., entrepreneurship, knowledge-based competition, corporate governance).

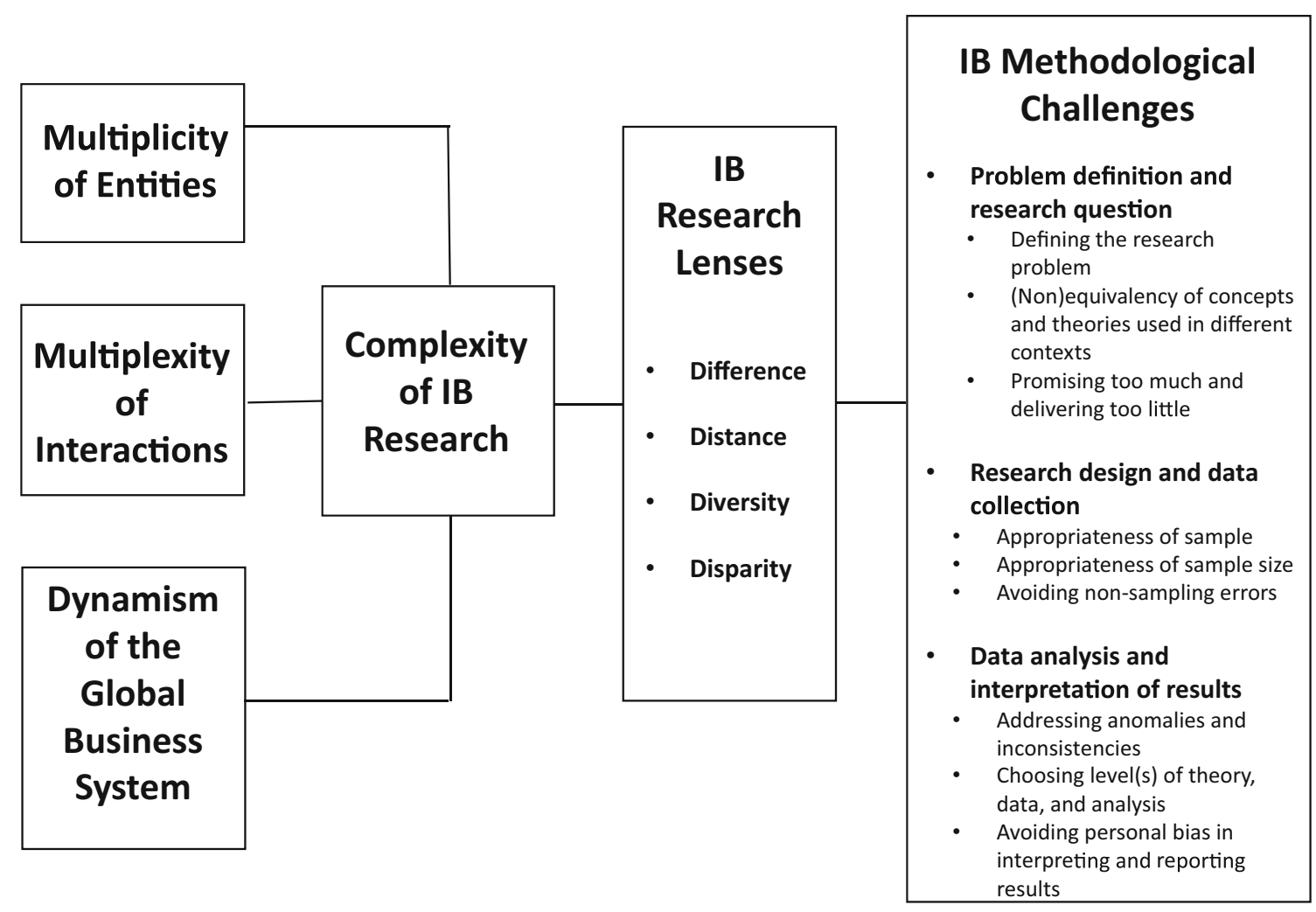

Figure 1 The complexity of international business research.

"networks of networks" (D'Agostino \& Scala, 2014), generating systemic problems such as cross-level effects, feedback loops, diffusion, and contagion. See, for example, Cardillo et al.'s (2013) analysis of the multiplexity of the international air transportation network and Gemmetto et al.'s (2016) study of the relationships and interdependencies of world trade flows; both papers use network theory to analyze the multiplexity of cross-border flows.

Buckley and Casson (2001) argues that rational actor approaches can be used to address multiplexity, pointing to information costs, dynamic optimization, real options, and game theory as appropriate techniques for handling the dynamism of the IB system. Other approaches to multiplexity include fuzzy-set qualitative comparative analysis, multi-level analysis techniques, and qualitative research (Eden et al., 2020; D'Agostino \& Scala, 2014; Ferriani, Fonti \& Corrado, 2012).

The third factor generating complexity for IB research is the global economy's inherent $d y$ namism (dynamics over time). By dynamism, we mean the various ways that time and history can affect a system such as trends, hysteresis, business cycles, crises, and other instabilities. The dynamism of the international business system generates risk, uncertainty, volatility, and ambiguity, providing both challenges and opportunities for decisionmakers. Many scholars have stressed the importance of history and time to IB research (e.g., Jones 
\& Khanna, 2006; Coviello \& Jones, 2004; Eden, 2009). Bringing dynamism into IB research can be done using a variety of research methods, including longitudinal case studies, real options approaches, event studies, and event history analysis. Each of these approaches also raises its own methodology challenges, some of which are discussed in Eden et al. (2020).

\section{Four Research Lenses on Complexity}

To analyze the complexity of the international business system, IB scholars have developed four research lenses, which we refer to as the "four D's" (difference, distance, diversity, and disparity) and illustrate in Figure 1. The first - "Difference" involves the relatively simple matter of comparing how "here" is different from "there" (e.g., crossborder comparisons of domestic with foreign). Early research in IB (e.g., the Ownership-Location-Internalization (OLI) paradigm) focused on the differences that businesses faced when they crossed national borders and one still regularly hears IB research referred to as "cross-border" or "crosscultural" studies. The focus of "Difference" is on the border as a metaphor for separating "here" (the known or us) from "there" (the unknown or them). Research on topics varying from offshore production to liability of foreignness to insiders and outsiders all share this crossing-a-border "Difference" lens.

"Distance" became a second important research lens for IB scholars after the introduction of new datasets and metrics that could be used to measure the cultural and institutional distances between countries. Early users of Hofstede's (1980) cultural dimensions, for example, explored the impact of cultural distance on foreign mode of entry (e.g., Kogut \& Singh, 1988). Distance studies, using these new datasets and metrics, have been a dominant theme of IB research for nearly 30 years (see reviews in Beugelsdijk, Ambos \& Nell (2018) and Maseland, Dow \& Steel (2018)).

"Diversity" - the third "D" - is a newer focus of IB researchers interested in exploring, for example, varieties of capitalism and variations within and across countries (see also Stahl, Tung, Kostova \& Zellmer-Bruhn, 2016). Diversity pays attention to the multiplicity of actors and networks and the multiplexity of their interactions. Diversity is inherent in multiplexity and may involve new research metrics and methods. Dai, Eden and Beamish (2013), for example, show how Coulombe's Law can be used to calculate the dynamic exposure faced by a foreign subsidiary surrounded by multiple war zones of different sizes at different distances and points of time. Peterson, Arregle and Martin (2012) provides a useful introduction to multilevel models that can be used to analyze diversity issues.

We believe that the fourth " $\mathrm{D}$ " - "Disparity" - is on the horizon and will become an important topic for IB researchers in the 2020s and 2030s. The call for IB researchers to engage more with global societal challenges (Buckley, Doh \& Benischke, 2017), the growing importance of the new group Responsible Research in Business and Management (http://www. rrbm.network), and the launch of the Journal of International Business Policy, all suggest more attention is being paid by IB scholars to the massive inequalities that exist across and within countries. The current global pandemic caused by COVID-19 is likely to exacerbate these cross-country disparities. We predict that more IB research in the future will examine the role that international business plays in society, in both ameliorating and exacerbating disparity and inequality, bringing their own research methodology challenges (Schlegelmilch \& Szöcs, 2020; Crane, Henriques \& Husted, 2018).

We therefore conclude that complexity - generated by the multiplicity of entities, multiplexity of interactions, and dynamism of the global economy - is the underlying cause of the unique methodological challenges facing international business research. The four lenses on complexity - difference, distance, diversity, and disparity - offer unique research challenges and opportunities for IB scholars and, as a result, have also presented them with unique research methodology problems, to which we now turn.

\section{COPING WITH THE COMPLEXITY OF IB RESEARCH}

We view complexity as the keyword that best captures IB research; that is, what it means to put the adjective "international" together with the noun "business" in the matrix that defines the "IB" field. Below we discuss the implications of complexity for the methodology challenges facing IB scholars. We organize these challenges according to the timeline of a typical IB research process, building on Nielsen, Eden and Verbeke (2020): (1) problem definition and research question, (2) research design and data collection, and (3) data analysis and interpretation of results. In each phase, we focus on the complexity issues that are prevalent and/or unique to IB research, the methodology challenges they pose, and recommend possible solutions (see Figure 1). 


\section{Phase 1: Problem Definition and Research Question}

In Phase 1, the researcher or research team must identify and define the problem and question(s) that will drive the project. Here, we see at least three methodological challenges.

\section{Defining the research problem}

IB requires attention to both the similarities and differences between and across domestic and foreign operations at multiple levels of analysis (e.g., firm, industry, country). Isolating the international (cross-border) aspects of a study requires a deep understanding of domestic and foreign environments. Thus, both the multiplicity of actors and multiplexity of interactions create complexity in defining the research problem. We suggest that looking at the research problem through the lenses of the "four D's" (difference, distance, diversity, and disparity) can provide an fruitful avenue for attending to the complex set of issues across multiple contextual dimensions, including setting, unit, location, and time.

\section{The (non)equivalency of concepts and theories used in different contexts}

Much IB research involves applying "standard" theories (e.g., internalization, transaction cost economics, resource-based view) to particular types of firms. However, the assumptions of these theories and their applicability are likely to vary across countries. IB scholars need to identify and account explicitly for contextual influences and their potential impacts on the design and interpretation of outcomes of their study. Contextual issues are critical for determining the boundaries within which particular theories may be applicable. Studies of state ownership, for example, may yield very different results when the state-owned multinationals are from China, Norway or Brazil, given the different institutional contexts of these countries. Once again, an explicit focus on the sources of complexity may help IB researchers discern how, why, where, and when concepts and theories are equivalent (or not) in different contexts.

\section{Promising too much and delivering too little}

While most scholars start with a "big" research question (e.g., how distance or diversity affects a particular MNE strategy), in practice, their empirical study is much more narrowly defined. IB scholars may end up overestimating the generalizability of their results, leading to exaggerated claims that "promise too much." Selection of the research question should drive the data collection and choice of methodology stages, and the way the results are reported and interpreted, not the other way around.

\section{Phase 2: Research Design and Data Collection}

In the second stage where researchers are engaged in research design and data collection, there are at least three core methodological challenges.

\section{Appropriateness of the sample}

IB scholars typically prefer to use data from secondary sources such as national and international (e.g., US and UN) statistical agencies and private firms (e.g., Thomson Reuters, Standard \& Poor's). However, particularly in developing countries, such data sources are either not available or are often of questionable quality. Moreover, IB researchers often assume implicitly that all sampled entities within-country share the same characteristics, with differences existing only across countries. This assumption may be wishful thinking as differences within countries (especially between rural and city areas in developing countries) may be larger than across countries, as noted by Peterson (2004). When the samples are inadequate, of course, the results will be problematic. Aguinis et al. (2020) identified idiosyncratic samples and contexts as a methodological concern in $62 \%$ of their sampled JIBS articles. We contend that a stronger focus on understanding the types of complexity during data collection may help prevent inadequate sampling in IB studies.

\section{Appropriateness of the sample size}

Typically, studies that examine the impact of independent variable $\mathrm{X}$ on the dependent variable $Y$ must hold constant other variables that can also affect $\mathrm{Y}$. Less attention is paid, however, to $\mathrm{X}$ itself. In an international context differences in $\mathrm{X}$ across countries may have many facets. For example, studying the influence of institutional distance $(\mathrm{X})$ on the MNE's mode of entry choice $(\mathrm{Y})$ requires unbundling institutional distance into different components, which may warrant a large sample size or more careful sample selection.

\section{Avoiding non-sampling errors}

Large multi-country datasets constructed from responses to governmental and private surveys are attractive to IB researchers because these datasets offer the opportunity to test IB research questions 
on much larger cross-country and cross-cultural samples. These datasets however can be problematic for IB research. First, more often the "breadth" (number of countries and number of constructs) of multi-country/culture surveys far exceeds their "depth" (number of years). Many may be single year surveys, raising reliability issues. Second, multi-country datasets - even when constructed with care - may be prone to non-sampling errors. Low measure reliability, for example, can arise from differences in assessment methods used "on the ground" across countries. Differences in how various cultures understand different constructs (e.g., what "gender equality" means) are also a problem. To this end, Chidlow, Ghauri, Yeniyurt and Cavusgil (2015) reported that establishment of translation equivalence in cross-cultural studies remains sparse with regards to whether (a) the instrument used to collect the required data is translated appropriately across different cultures and (b) the data collection procedures are comparable across different cultures. A third challenge is that IB researchers may be either unaware (or choose to ignore) changes in methods and sources used by national and international agencies to collect and publish their datasets. Lacking in-depth knowledge of a dataset raises the likelihood of its misuse and misinterpretation of the results.

In sum, non-sampling errors may bedevil IB research simply because IB research questions do not "travel well" cross-nationally and cross-culturally due to multiplicity, multiplexity, and dynamism. One solution to the problem of possible measurement non-equivalence is to test for this issue before using the datasets. Nielsen et al. (2020) provides examples of statistical methods that can test for measurement equivalence on a cross-national/cultural basis. Aguinis et al. (2020) provides more generic examples of how data collection and research design challenges may be dealt with; for example, they focus on the potential virtues of Big Data, though such approaches should be used carefully so they do not confound rather than resolve non-sampling errors in IB research.

\section{Phase 3: Data Analysis and Interpretation of Results}

IB scholars also face special issues when they are engaged in data analysis and interpretation of results. We briefly discuss three research methodology challenges which can be added to the more general issue of establishing causality (across contexts, levels, and time) raised by Aguinis et al. (2020).

\section{Addressing anomalies and inconsistencies}

Outliers and other anomalies and inconsistencies may be more prevalent in multi-country than in single country studies due to the complexity of IB research. Rare events and asymmetric, longtailed distributions may be more prevalent in international settings, necessitating research methods designed to handle these anomalies (Andriani \& McKelvey, 2007). For instance, ignoring the "elephant in the room" (e.g., the dominance of one country such as China or the United States in a multi-country dataset) can lead to erroneous conclusions based on Gaussian averages (e.g., about the average scale and scope of internationalization). Moreover, as datasets span multiple countries and contexts - often relying on combining data sources from different entities and countries - the likelihood of errors due to anomalies and inconsistencies in data collection methods, cleaning, and handling, including translational and equivalence issues, increases. IB researchers must take appropriate steps to correct for such biases, for example, by using investigator triangulation ex ante during data collection and ex post during analysis and reporting (Nielsen et al., 2020).

\section{Choosing the level(s) of theory, data, and analysis} IB studies, as we have stressed above, involve multiplicity and multiplexity. They are typically not only multi-country and multi-context but also multi-level. Employees are nested (and may be cross-nested) within subunits of an MNE (e.g., parent, regional headquarters, plants, branches, subsidiaries); the MNE itself is cross-nested within multiple national and institutional contexts depending on its global footprint. Thus, studying an MNE - let alone a comparison across MNEs - is an exercise in studying and understanding multilevel heterogeneity (individual, plant, firm, industry, country) as well as cross-nested embeddedness at each of these levels (Nielsen \& Nielsen, 2010). Not surprisingly, determining the "right" level or levels of theory, data, and analysis needed to address a particular research question is not easy. An extension of this research problem arises from ecological fallacies where a construct developed for use at one level of analysis (e.g., country) is used at a different level (e.g., firm), without attention paid to the possible consequences. The "four D's" may provide useful lenses through which to examine 
the multiplicity and multiplexity inherent in issues of levels of theory, data, and analysis, that give rise to additional layers of interdependence and nesting.

\section{Avoiding personal bias in interpreting and reporting results}

We all "see through our own lenses." IB researchers, given their interest in the four D's, are likely to be more contextually aware than domestically focused but are still likely to suffer from personal and institutional biases. Working with diverse teams of scholars from other countries, cultures, and disciplines can help reduce the influence of personal biases. Multi-country/cultural research teams can also provide benefits to IB research by improving the ability of concepts and theories to "travel" across countries, as argued in Peterson (2004).

\section{CONCLUSION: WORDS TO LIVE BY}

We agree with Aguinis et al. (2020) that IB scholarship suffers from methodological challenges. IB research, by its nature, involves a high degree of complexity generated by the multiplicity, multiplexity, and dynamism of the global economy. IB scholars can use the four D's (difference, distance, diversity, and disparity) as useful lenses for understanding and analyzing this complexity. Complexity, of course, is one of the reasons that so many scholars study IB research questions but it also brings a set of methodological challenges unique to IB research.

We end with four pieces of advice that we hope provide useful guidance for IB researchers. We note that these guiding principles are complementary to the solutions proposed in Aguinis et al. (2020) and to our methodology recommendations above.

\section{Learn to Live with (and Embrace) Complexity in Research Design}

Complexity is a word that strikes fear and dread into the heart of most researchers; the more complex the problem, the more difficult the research tasks that lie ahead. We argue that IB researchers must learn to live with (and embrace) complexity. They must be comfortable with the multiplicity, multiplexity, and dynamism that characterize the global economy. Deconstructing a research question to examine its complexity through the lens of one or more of the four D's (difference, distance, diversity, and disparity) is, we argue, critically important for developing interesting, useful, and impactful research. Using these lenses can help the IB researcher understand how multiple parameters affect his or her variable(s) of interest, often in non-linear and interdependent ways. As a result, relying on secondary data sources and conventional research methods such as OLS regression are likely to be insufficient or inappropriate to understand the complexity of IB research. Rather, embracing complexity naturally leads to more experimental research designs, as well as mixed methods, and/or multilevel analyses. Research designs that explicitly acknowledge complexity are likely to better answer the "big" questions that IB faces now and in the future.

\section{Use Triangulation Actively to Increase Rigor and Relevance}

Looking at a phenomenon or issue from multiple angles - not the least methodological - can address the biases, errors, and limitations introduced by any single approach (Denzin, 1978; Jick, 1979). Most of the IB-specific challenges we have raised above can be directly addressed by incorporating various types of triangulation strategies into the research design. For instance, theoretical triangulation may lead to new research questions by juxtaposing different theoretical perspectives. Similarly, data source and data collection triangulation may be seen as "an opportunity to go deeper, rather than as a limitation" (Aguinis et al., 2020) while also increasing sample reliability and reducing nonequivalence biases. Analytical triangulation helps ensure validity and reliability of results by comparing and contrasting results using multiple analytical techniques. Investigator triangulation may reduce personal biases in both data collection, analysis, and interpretation processes (Nielsen et al., 2020). Indeed, we would argue that the four D's (difference, distance, diversity, and disparity) may best be attended to by carefully building triangulation into the research design process.

\section{Exercise Due Diligence and Good Judgment}

IB researchers should spend time, up front, understanding their research question and their unit of analysis, mapping and graphing the hypothesized relationships among their variables, and taking account of previously theorized relationships. Investment in building a thorough understanding of the research problem will help point the way to the most appropriate research method(s) and technique(s) for tackling the problem. Rules of thumb as to what constitutes an "acceptable" 
methodological approach are a poor substitute for the due diligence necessary to enable the researcher to exercise his or her good scholarly judgment. This piece of advice also requires IB researchers to have a good command of the available different research methods, of where they work well and where they do not.

\section{Engage in Ethical and Responsible Research Practices}

There have been many articles on best practices in responsible research, including several by Herman Aguinis that are particularly appropriate for IB researchers (Aguinis et al., 2017, 2018, 2019; Bergh et al., 2017). In addition, Anne Tsui and colleagues have been actively encouraging business and management scholars to join RRBM (Responsible Research in Business and Management; https:// www.rrbm.network) and adopt RRBM best practices

\section{REFERENCES}

Aguinis, H., Cascio, W. F., \& Ramani, R. S. 2017. Science's reproducibility and replicability crisis: International business is not immune. Journal of International Business Studies, 48(6): 653-663.

Aguinis, H., Hill, N. S., \& Bailey, J. R. 2019. Best practices in data collection and preparation: Recommendations for reviewers, editors, and authors. Organizational Research Methods. https:// doi.org/10.1177/1094428119836485.

Aguinis, H., Ramani, R. S., \& Alabduljader, N. 2018. What you see is what you get? Enhancing methodological transparency in management research. Academy of Management Annals, 12(1): 83-110.

Aguinis, H., Ramani, R. S., \& Cascio, W. F. 2020. Methodological practices in international business research: An after-action review of challenges and solutions. Journal of International Business Studies. https://doi.org/10.1057/s41267-020-003537.

Andersen, P. H., \& Skaates, M. A. 2004. Ensuring validity in qualitative international business research. In R. MarschanPiekkari \& C. Welch (Eds.), Handbook of qualitative research methods for international business: 464-485. Cheltenham: Edward Elgar.

Andriani, P., \& McKelvey, B. 2007. Beyond Gaussian averages: redirecting international business and management research toward extreme events and power laws. Journal of International Business Studies, 38, 1212-1230.

Bergh, D. D., Sharp, B. M., Aguinis, H., \& Li, M. 2017. Is there a credibility crisis in strategic management research? Evidence on the reproducibility of findings. Strategic Organization, 15(3): 423-436.

Beugelsdijk, S., Ambos, B., \& Nell, P. C. 2018. Conceptualizing and measuring distance in international business research: Recurring questions and best practice guidelines. Journal of International Business Studies, 49(9): 1113-1137.

Brutus, S., Aguinis, H., \& Wassmer, U. 2013. Self-reported limitations and future directions in scholarly reports: Analysis and recommendations. Journal of Management, 39(1): 48-75.

Buckley, P. J., \& Casson, M. 2001. Strategic complexity in international business. In A. M. Rugman \& T. L. Brewer (Eds.), The Oxford handbook of international business (1st ed.): 88-126. Oxford: Oxford University Press. for their research. The editors of JIBS have also led the way for many years in articulating best ethical and responsible practices for IB research, e.g., through the AIB Journals Code of Ethics, JIBS editorials at https://www.palgrave.com/gp/journal/ 41267/volumes-issues/editorials, and the new JIBS Special Collections books, in particular, Research Methods in International Business (Eden et al., 2020). We conclude that "ethical" and "responsible" are good words to live by. Words that when practiced by the global community of IB scholars will build knowledge for a more prosperous, just, and sustainable world.

\section{ACKNOWLEDGEMENTS}

We thank Alain Verbeke and Stewart Miller for helpful comments on earlier drafts of this paper.

Buckley, P. J., Doh, J. P., \& Benischke, M. H. 2017. Towards a renaissance in international business research? Big questions, grand challenges, and the future of IB scholarship. Journal of International Business Studies, 48(9): 1045-1064.

Cardillo, A., Gomez-Gardenes, J., Zanin, M., Romance, M., Popo, D., del Pozo, F., et al. 2013. Emergence of network features from multiplexity. Scientific Reports, Nature Research, 3(1344): 1-6. https://doi.org/10.1038/srep013441.

Chidlow, A., Ghauri, P., Yeniyurt, S., \& Cavusgil, S. T. 2015. Establishing rigor in mail-survey procedures in international business research. Journal of World Business, 50(1): 26-35.

Coviello, N. E., \& Jones, M. V. 2004. Methodological issues in international entrepreneurship research. Journal of Business Venturing, 19(4): 485-508.

Crane, A., Henriques, I., \& Husted, B. W. 2018. Quants and poets: Advancing methods and methodologies in business and society research. Business and Society, 57(1): 3-25.

Cuypers, I. R. P., Ertug, G., Cantwell, I., Zaheer, A., \& Kilduff, M. 2020. Making connections: Social networks in international business. Journal of International Business Studies, 51,: 714-736.

D'Agostino, G., \& Scala, A. (Eds.). 2014. Networks of networks: The last frontier of complexity. Cham: Springer.

Dai, L., Eden, L., \& Beamish, P. 2013. Place, space, and geographic exposure: Foreign subsidiary survival in conflict zones. Journal of International Business Studies, 44(6): 554-578.

Denzin, N. K. (Ed.) 1978. Triangulation: A case for methodological evaluation and combination. In Sociological methods: A sourcebook (pp. 339-357). New York, NY: McGraw-Hill.

Eden, L. 2008. Letter from the editor-in-chief. Journal of International Business Studies, 39(1): 1-7.

Eden, L. 2009. Letter from the Editor-in-Chief: Time in international business. Journal of International Business Studies, 40(4): 535-538.

Eden, L., Dai, L., \& Li, D. 2010. International business, international management, international strategy: What's in a name?. International Studies of Management and Organization, 40(4): 54-68.

Eden, L., Nielsen, B. B., \& Verbeke, A. (Eds.). 2020. Research methods in international business. JIBS Special Collections. London: Palgrave Macmillan. 
Ferriani, S., Fonti, F., \& Corrado, R. 2012. The social and economic bases of network multiplexity: Exploring the emergence of multiplex ties. Strategic Organization, 11(1): 7-34.

Gemmetto, V., Squartini, T., Picciolo, F., Ruzzenenti, F., \& Garlaschelli, D. 2016. Multiplicity and multireciprocity in directed multiplexes. Physical Review, 94(042316): 1-20. https://doi.org/10.1103/physreve.94.042316.

Hofstede, G. 1980. Culture's consequences: International differences in work-related values. Beverly Hills: Sage.

jick, T. D. 1979. Mixing qualitative and quantitative methods: Triangulation in action. Administrative Science Quarterly, 24(4): 602-611.

Jones, G., \& Khanna, T. 2006. Bringing history (back) into international business. Journal of International Business Studies, 37(4): 453-468.

Kogut, B., \& Singh, H. 1988. The effect of national culture on the choice of entry mode. Journal of International Business Studies, 19(3): 411-432.

Maseland, R., Dow, D., \& Steel, P. 2018. The Kogut and Singh national cultural distance index: Time to start using it as a springboard rather than a crutch. Journal of International Business Studies, 49(9): 1154-1166.

Nielsen, B. B., \& Nielsen, S. 2010. A multilevel approach to understanding the multinationality-Performance relationship. In T. M. Devinney, T. Pedersen, \& L. Tihanyi (Eds.), The past, present and future of international business and management: 527-557. Bingley: Emerald Group Publishing Limited.

Nielsen, B. B., Eden, L., \& Verbeke, A. 2020. Research methods in international business: Challenges and advances. In L. Eden, B. B. Nielsen, \& A. Verbeke (Eds.), Research methods in international business, JIBS Special Collections: 3-41. London: Palgrave Macmillan.

Nielsen, B. B., Welch, C., Chidlow, A., Miller, S., Aguzzoli, R., Gardner, E., et al. 2020. 50 years of methodological trends in
JIBS: Why future IB research needs more triangulation. Journal of International Business Studies. https://doi.org/10.1057/ s41267-020-00372-4.

Peterson, M. F., Arregle, J.-L., \& Martin, X. 2012. Multilevel models in international business research. Journal of International Business Studies, 43(5): 451-457.

Peterson, R. B. 2004. Empirical research in international management: A critique and future agenda. In R. MarschanPiekkari \& C. Welch (Eds.), Handbook of qualitative research methods for international business: 25-55. Cheltenham: Edward Elgar.

Samuels, W. J. 1995. Some thoughts on multiplicity. Journal of Economic Methodology, 2(2): 287-291.

Schlegelmilch, B. B., \& Szöcs, I. 2020. Rethinking business responsibility in a global context. Cham: Springer.

Stahl, G. K., Tung, R. L., Kostova, T., \& Zellmer-Bruhn, M. 2016. Widening the lens: Rethinking distance, diversity, and foreignness in international business research through positive organizational scholarship. Journal of International Business Studies, 47(6): 621-630.

Teagarden, M. B., Von Glinow, M. A., \& Mellahi, K. 2018. Contextualizing international business research: Enhancing rigor and relevance. Journal of World Business, 53(3): 303-306.

Verbeke, A., \& Ciravegna, L. 2018. International entrepreneurship research versus international business research: A false dichotomy? Journal of International Business Studies, 49(4): 387-394.

Publisher's Note Springer Nature remains neutral with regard to jurisdictional claims in published maps and institutional affiliations.

Accepted by Alain Verbeke, Editor-in-Chief, 4 September 2020. This article was single-blind reviewed. 